\title{
Biology and language revisited
}

\author{
JAMES DEESE \\ University of Virginia, Charlottesville, Virginia
}

\section{Language and Species}

By Derek Bickerton. 1990, Chicago: University of Chicago Press. 304 pp. \$24.95.

The French Academy in the late 19th century banned all discussion of the origin and evolution of language on the grounds that it was but useless speculation. On reading Bickerton's book, I am inclined to agree with the judgment of the Academy. I think a psychobiologist would do well to avoid this book if he/she expects it to contain some new insight or to recount some important discoveries in the psychobiology of language. On the other hand, there are reasons for supposing that the Academy's judgment was a bit too harsh. In the past generation, there have been several interesting, important, and even plausible essays into the evolution of language. Although Eric Lenneberg's Biological Foundations of Language is now nearly a quarter of a century old, it contains ideas and data that not only have the merit of being more insightful than anything Bickerton gives us but some possibility of being declared to be correct or not. To be sure, Lenneberg's book is out of date (he makes no mention of the split-brain literature, although the beginnings were available to him), but Lenneberg deals with problems that still enliven the pages of the journal Brain and Language. Philip Lieberman's little book, On the Origins of Language, is another reason why the French Academy's judgment went too far. Lieberman has a specific hypothesis about the physical (not neurological) features that made language possible. Although he has had to defend his evidence furiously in the pages of Brain and Language, his ideas are intriguing and have some consequence.

I mention Lenneberg and Lieberman because their books and their approach to the problem of the biology

Correspondence concerning this review should be addressed to James Deese, Department of Psychology, Gilmer Hall, University of Virginia, Charlottesville, VA 22903-2477. of language have some of the character of genuine science. Bickerton's book does not. Now, to be sure, the reader uninformed about linguistic sciences over the past 30 years or so might learn something from reading Bickerton. There is a reasonable discussion of linguistic theory, although one might conclude from reading it that linguistic theory ended with Chomsky. I myself am not enthusiastic about current theories of grammar, but they are there, and anyone writing such a broad and eclectically based book as Bickerton's has some obligation to mention them. The brief material on aphasia is sensible; the discussion of the perennial brain/body size relation is primitive and uninformed. I cannot comment with any sense of confidence on the material concerning what might be called human ethology, but it strikes me as being driven more by a particular, though unstated, view of ethics than by the science of human ethology. The reader who knows little about the modern philosophy of language might learn something from Bickerton, but he/she might learn more from any one of a number of sources.

What of Bickerton's central thesis? Having said so many negative things about his book, I shall relieve the publisher by withholding comment about it, save to say that the interested reader should check for him/herself. It does, however, draw upon a naive account of signing in apes, the developmental sequence of language in human children, and (to give the devil his due) a more sophisticated (but wrongheaded) application of the data on pidgin languages. The linguistically sophisticated reader will know that there is something called proto-Indo-European, a triumph of linguistic reconstruction. Its success was followed by many secondary successes, for example, proto-Athapaskan. Bickerton attempts to do the same for the whole of human language. He postulates a "protolanguage." I am afraid the attempt is an empty one.

(Manuscript received February 18, 1991; accepted for publication February 21, 1991.) 